\title{
The detour paradigm in animal cognition
}

\author{
Can Kabadayi $^{1}\left[\right.$ Katarzyna Bobrowicz ${ }^{1} \cdot$ Mathias Osvath $^{1}$
}

Received: 23 July 2017 / Revised: 11 November 2017 / Accepted: 7 December 2017 / Published online: 12 December 2017

(c) The Author(s) 2017. This article is an open access publication

\begin{abstract}
In this paper, we review one of the oldest paradigms used in animal cognition: the detour paradigm. The paradigm presents the subject with a situation where a direct route to the goal is blocked and a detour must be made to reach it. Often being an ecologically valid and a versatile tool, the detour paradigm has been used to study diverse cognitive skills like insight, social learning, inhibitory control and route planning. Due to the relative ease of administrating detour tasks, the paradigm has lately been used in large-scale comparative studies in order to investigate the evolution of inhibitory control. Here we review the detour paradigm and some of its cognitive requirements, we identify various ecological and contextual factors that might affect detour performance, we also discuss developmental and neurological underpinnings of detour behaviors, and we suggest some methodological approaches to make species comparisons more robust.
\end{abstract}

Keywords Detour behavior · Inhibitory control $\cdot$ Route planning $\cdot$ Comparative psychology

\section{Introduction}

One of the oldest paradigms in animal cognition research involves the use of a see-through obstacle that must be detoured in order to reach the visible goal on the opposite side. Studies on such detour behaviors date back to the beginning of the twentieth century. Hobhouse (1901) tested dogs who could see their owner through a window, and to reach him they had to make a detour and use the door of the house. Thorndike (1911) investigated whether chickens and fish will make roundabouts when a wire or glass barrier blocks the shortest path to a goal room. According to both authors, successful detours exemplify actions that are not solely governed by innate mechanisms because otherwise the animals would head straight for the visible goal.

A decade later, the detour paradigm was employed by the Gestalt psychologist Wolfgang Köhler. He tested chimpanzees, dogs and chickens when they faced a wire fence barrier with a reward on the other side. His aim was to

Electronic supplementary material The online version of this article (https://doi.org/10.1007/s10071-017-1152-0) contains supplementary material, which is available to authorized users.

Can Kabadayi

can.kabadayi@lucs.lu.se

1 Department of Cognitive Science, Lund University, Helgonavägen 3, 22100 Lund, Sweden study their potential "insight" capacities. He believed that detours, which required moving away from the goal in order to ultimately reach it, were good tests of whether the goaldirectedness was first worked out in the mind (Köhler 1925).

Since then, the detour paradigm has been used in at least 127 studies on at least 96 species, and it has been varied in different ways and used to measure diverse cognitive skills (Table 1, Online Resource 1). The paradigm has also been used in developmental studies on human children, and in neuropsychological studies. In recent years, detour tasks have been employed for large-scale comparative research into the evolution of complex cognitive skills (Kabadayi et al. 2016, 2017a; MacLean et al. 2014). Amidst the evergrowing number of species being tested on various detour tasks, it is time to take stock and look closer at the detour paradigm and the cognitive skills it measures.

Here we review the detour paradigm within in the field of animal cognition. First, we discuss different types of detour tasks in relation to the cognitive skills they address. We examine various factors that may influence detour behaviors, including ecological, evolutionary and task-specific factors. We also review relevant developmental studies, and those investigating the neurological underpinnings of successful detour behavior. Special attention is paid to the contemporary use of detour tasks as a measure of inhibition. We end with recommendations for future studies. 
Table 1 Overview of the cognitive skills measured in the detour paradigm

\begin{tabular}{|c|c|}
\hline Tested skills & Explanation \\
\hline Cognitive and motor development & $\begin{array}{l}\text { The execution of reaching and locomotor detours become stabilized throughout infancy, indicating } \\
\text { development of inhibitory control and motor development (Bojczyk and Corbetta 2004; Diamond 1990; } \\
\text { Lockman 1984) }\end{array}$ \\
\hline Functional generalization & $\begin{array}{l}\text { Subjects perceive the functional similarity between detour setups that differ in various perceptual features, } \\
\text { and they transfer between tasks accordingly (Lockman and Adams 2001) }\end{array}$ \\
\hline Inhibitory control & $\begin{array}{l}\text { The visible reward behind the barrier creates a strong prepotent tendency for a direct reach. Subjects } \\
\text { inhibit this strong perceptual pull and instead execute detour behavior (Diamond 1990) }\end{array}$ \\
\hline Insight & $\begin{array}{l}\text { A correct solution of the detour problem already on the first trial involves a mental operation where the } \\
\text { subject manipulates the problem as a whole and thereafter executes the right response (Köhler 1925; } \\
\text { Lorenz 1932) }\end{array}$ \\
\hline Learning & $\begin{array}{l}\text { Repeated testing of the subjects on detour problems can reveal various learning processes and phenom- } \\
\text { ena such as spatial learning, trial-and-error learning, critical learning period during development, and } \\
\text { disruption and retention mechanisms (Fischel 1933; Hull 1938; Scholes 1965; Thorndike 1911) }\end{array}$ \\
\hline Social learning & $\begin{array}{l}\text { Subjects learn the detour solution by observing another individual demonstrating it (Pongrácz et al. 2005, } \\
\text { 2008; Wilkinson et al. 2010) }\end{array}$ \\
\hline Task switching & $\begin{array}{l}\text { Subjects switch their previously reinforced detour responses if a shortcut option becomes available, and } \\
\text { vice versa (Parker et al. 2005; Smith and Litchfield 2010; Thorndike 1911) }\end{array}$ \\
\hline Working memory and route planning & $\begin{array}{l}\text { When the goal becomes invisible, subjects rely on working memory of the position of the goal, and they } \\
\text { plan their detour routes in the absence of perceptual cues emanating from the goal (Cross and Jackson } \\
\text { 2016; Wells 1967) }\end{array}$ \\
\hline
\end{tabular}

The review is limited to tasks which require detours to reach a goal behind a barrier when this is visible from the animal's starting position. Following Köhler (1925) and Chapuis (1987), we distinguish between two overarching setups:

(a) The goal is visible behind the barrier throughout the detour response (continuously visible goal detours).

(b) The goal is initially visible behind the barrier, but it becomes invisible for a certain duration while the animal is moving, due to some added visual occlusions along the way (initially visible goal detours).

Although different detour tests share an underlying characteristic - the direct path to the goal is blocked and a roundabout way must be taken - they also differ considerably in their perceptual features (Fig. 1). Locomotor detours often require the subject to move its entire body around the barrier, whereas reaching detours require a reach only with a limb. Moreover, the barriers come in different shapes (U-, V-, I-, L-, J-shaped) and materials. Some barriers are fully transparent (e.g., glass), and some are semitransparent (e.g., fence/mesh). Semitransparent barriers can in turn have horizontal or vertical grid patterns, or both (Online Resource 1). Variation in such perceptual features often affects the detour performance (Table 2).

\section{Cognitive mechanisms investigated with the detour paradigm}

\section{Inhibitory control}

Köhler (1925, p.11) begins the first chapter of his influential book, The Mentality of the Apes, with the following paragraph: "When any of those higher animals, which make use of vision, notice food (or any other objective) somewhere in their field of vision, they tend-so long as no complications arise- to go after it in a straight line. We may assume that this conduct is determined without any previous experience, providing only that their nerves and muscles are mature enough to carry it out." To contrast such behaviors, he then describes situations where a direct way to the target is blocked, and the animal thus must make a detour to reach the goal. Such situations would require some mental operations beyond innate responses.

Köhler (1925) described his observations on dogs, chickens and chimpanzees making detours around wire fences. Whereas dogs and chimpanzees were usually successful, chickens had difficulties and often attempted to go directly for the food through the fence. But he also found individual variation within the species, and later studies have shown remarkable detour performances in chickens, even within few days after hatching (Regolin et al. 1994, 1995; Scholes 1965; Scholes and Wheaton 1966).

As Köhler notes, the goal visibility behind the barrier is one of the major factors influencing detour performance. A 


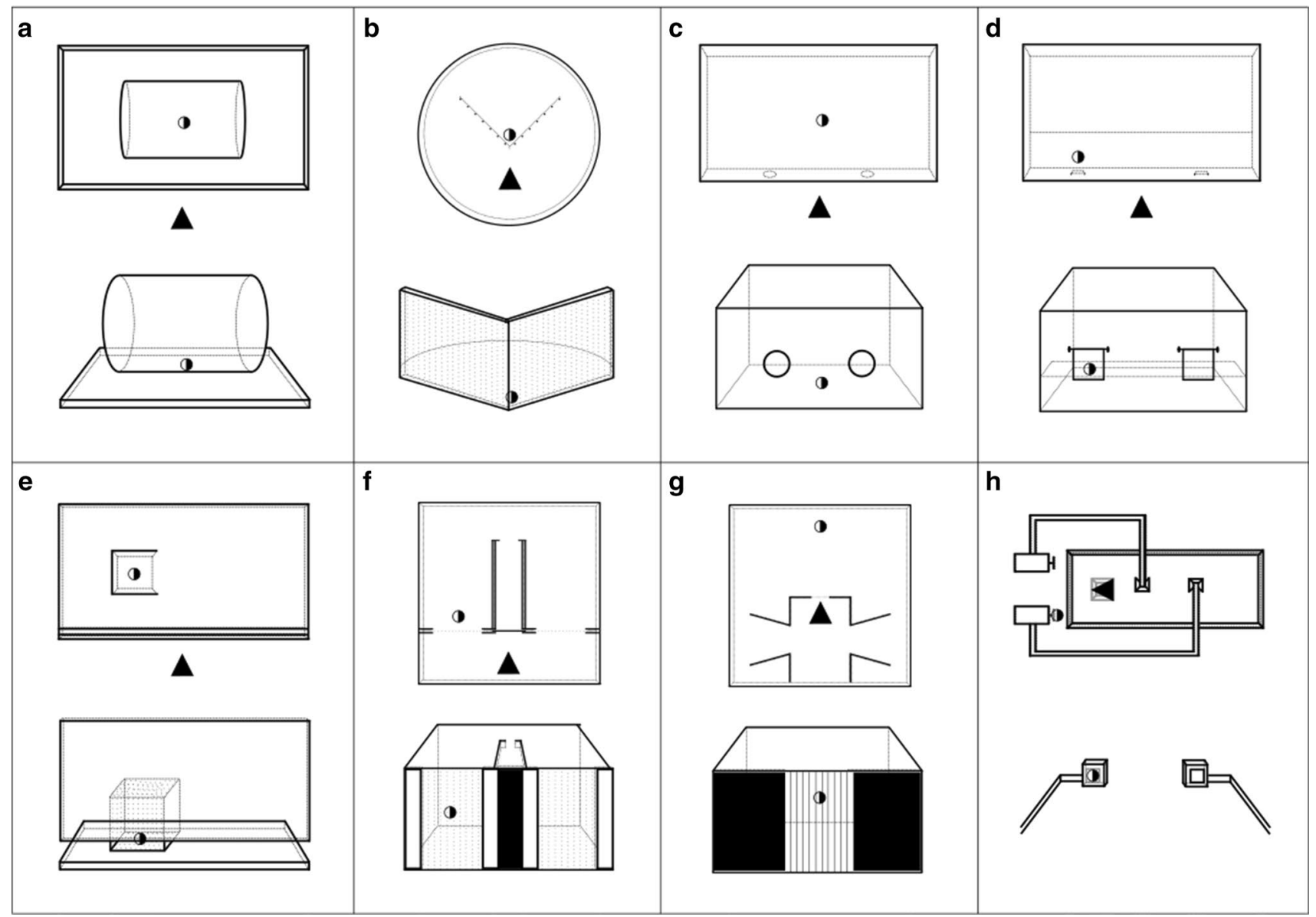

Fig. 1 A display of eight of the most common setups in detour tasks; each setup comes with two symbols: a half-filled circle (a goal), and a filled triangle (a subject), and occupies a separate panel. Within each panel, the upper figure shows the bird-eye view, while the lower figure the first-person view. The setups belong to the following tasks: a the cylinder task requires a reaching detour through one of the side openings of the transparent cylinder. b Inward detour task requires locomotion detour around a V-shaped transparent/fence barrier. c Plexiglas-hole task requires a reaching detour through one of the two holes in a Plexiglas panel placed upright between the subject and the reward. d Swing-door task requires a reaching detour through the door that is furthest from the goal. The doors can only be opened by pushing them forward, and an attempt to open the door that is closer to the goal results in the goal falling backwards and becoming out of reach. e Detour reaching task (object-retrieval task) requires a reaching detour through the side opening of the transparent box. The box has only one opening, which allows changing the open side facing the subject across trials. f Delayed-detour task requires passing by an opaque corridor and in the end selecting between two paths, only one of which leads to the goal room. g Four-compartment box task requires the subject to turn its back to the goal and choose among four doors, only two of which lead to the goal room. $\mathbf{h}$ Detour-choice task requires the subject to turn its back to the goal that is placed on top of a tower, and select among two poles, only one of which leads to the tower where the goal is placed common finding in detour studies is that detours become harder to perform if the goal behind the barrier is more clearly visible, e.g., when the occlusion is reduced through mesh grids or Plexiglas barriers (chickens: Regolin et al. 1994; dogs: Brucks et al. 2017; human infants: Lockman and Adams 2001; mice: Juszczak and Miller 2016, ring doves and pigeons: Miller and Tallarico 1974). Some researchers argue the visible reward behind the barrier acts like a "perceptual magnet," creating a prepotent tendency for a direct reach (Vallortigara and Regolin 2002). This makes it difficult to move away from the visible goal as a detour requires. In line with this, many species are better in making detours around opaque barriers compared to almost identical but transparent ones (cats: Poucet et al. 1983; chickens: Regolin et al. 1994; dogs: Chapuis et al. 1983; human infants: Lockman 1984, Noland 2008; mice: Juszczak and Miller 2016, although see Osthaus et al. 2010).

Similar to goal visibility, the distance to the goal affects detour behaviors: with increasing goal distance, it becomes easier to execute detours (chickens: Regolin et al. 1995; dogs: Köhler 1925; human infants: Diamond and Gilbert 1989; long-tailed macaques: Junghans et al. 2016; toads: Lock and Collett 1979). This suggests a closer goal creates a stronger lure which makes it harder to move away from. The 
Table 2 Several factors that may affect the detour performance

\begin{tabular}{ll}
\hline Factor & Examples \\
\hline Distance to the goal & $\begin{array}{c}\text { Increased goal distance makes it easier to execute detours (Diamond 1990; Junghans et al. 2016; Köhler 1925; Rego- } \\
\text { lin et al. 1994) } \\
\text { Animals tend to perform worse when they are in a fearful state, e.g., when tested alone in a novel environment } \\
\text { Neophobia }\end{array}$ \\
$\begin{array}{l}\text { Orientation of the barrier } \\
\text { In V-shaped barriers, dogs and goats perform better detours when they have to take outward detours compared to } \\
\text { inward detours (Nawroth et al. 2016; Pongracz et al. 2001). Chickens execute better detours with horizontal grid } \\
\text { pattern fence barriers compared to vertical grid ones, likely because the vertical grid barriers offer better goal vis- } \\
\text { ibility for a moving animal (Regolin et al. 1994) }\end{array}$ \\
$\begin{array}{l}\text { Since the transparent objects are artificial, animals lacking previous experience with them might initially fail on the } \\
\text { transparent barrier tasks because they did not learn that they cannot pass through transparent material. It takes } \\
\text { transparent objects } \\
\text { experience to resolve the tactile-visual conflict presented with the transparent barriers (Bojczyk and Corbetta 2004) } \\
\text { Data suggest that animals raised in enriched environments perform better in detour tasks compared to those raised in } \\
\text { low enriched environments (Clarke et al. 1951) }\end{array}$ \\
$\begin{array}{l}\text { The increased visibility of the reward behind the barrier creates a perceptual pull for a direct reach, thus making it } \\
\text { harder to execute detour response (Chapuis et al. 1983; Juszczak and Miller 2016; Lockman 1984; Lockman and } \\
\text { Reward visibility } \\
\text { Adams 2001; Poucet et al. 1983; Regolin et al. 1994; Zucca et al. 2005) } \\
\text { Type of the reward behind the barrier as well as the motivational and physiological state of the animal can affect the } \\
\text { detour response (Regolin et al. 1995; Shaw 2017) } \\
\text { Younger individuals might fail on detour tasks due to cognitive/motor immaturity (Diamond 1990; Lockman 1984) }\end{array}$ \\
$\begin{array}{l}\text { Motivation } \\
\text { Age }\end{array}$
\end{tabular}

effect of goal distance on detours has also been the subject of various theoretical analyses on detour behavior (Hull 1938; Lewin 1933; Tolman 1932; reviewed in: Rashotte 1987).

Such findings have led to the interpretation of detour tasks as a measure of executive functions, and more precisely of behavioral/motor inhibition: the subject must inhibit the predominant motor response of directly reaching for the reward and instead make a detour (Diamond 1990, 1991; Moll and Kuypers 1977). The fact that most subjects execute efficient detours around opaque barriers while having problems with identical but transparent barriers suggests a knowing/acting mismatch that is common to other inhibition tasks: the subjects know the detour solution; however, they cannot act on the knowledge because the visible reward creates a strong lure for a direct reach, thus bumping into the barrier (Diamond 2013).

Detour tasks have been used to study inhibitory control in development (see "The development of detour behaviors" section), in neurocognition (see "Neurological underpinnings of detour behaviors" section), and in inter-species comparisons (see "Ecological factors" section). The relative practical ease of using such tasks has begun to turn detour tasks into one of the benchmark tests of inhibition in inter-species comparisons and phylogenetic reconstructions (Amici et al. 2008; Kabadayi et al. 2016; MacLean et al. 2014; Vlamings et al. 2010). However, there is an ongoing discussion of the interpretation of the results concerning the vast sensorimotor variation among the tested species, numerous non-cognitive contextual factors that may affect performance (Table 2), and the learning/ceiling effects sometimes seen over trials (see "Learning" section).
In general, detour tasks, which are used to measure inhibitory control, belong to continuously visible goal detours, where the goal is visible behind the barrier throughout the detour response (Fig. 1a-e). For example, reaching detours belong to this category, where the subject uses its limb to retrieve a goal from the side opening of a transparent box or cylinder (Diamond 1990; MacLean et al. 2014, Fig. 1a, e). Performances in such visible conditions are sometimes juxtaposed with non-visible conditions (opaque apparatuses), in order to control for the effect of goal visibility (Diamond 1990; Lockman 1984).

\section{Working memory and route planning}

Even though initially visible goal detour setups can be used for testing inhibition, they are more suitable for studying working memory and route planning. In such tasks, the animals arguably form some sort of a mental representation of the goal position, which they then keep in mind for a given amount of time when the goal goes out of sight.

As described, in initially visible goal detour tasks the goal behind the barrier is visible from the starting position, but becomes out of view when the animal moves. This is usually achieved by opaque walls along the detour path or in some parts of the barrier itself (Fig. 1f). A majority of such detour setups also require a choice between multiple routes, only a subset of which lead to the goal (Fig. 1f-h). During this selection, the animals cannot see the goal.

For example, octopuses (Octopus vulgaris) have been tested in such design, also known as a delayed-detour test (Schiller 1949a, b; Wells 1964, 1967, 1970). In these 
experiments, the rewards were visible behind a barrier from the starting position. To reach the reward, the animals had to move forward into an opaque corridor, and choose between two openings at the exit, with only one opening leading to the reward room (Fig. 1f). The octopuses successfully completed around three out of every four trials.

Similarly, jumping spiders have been tested on initially visible goal detour tasks, where the individual, from the starting position, could see a distant goal placed on top of a pole (Fig. 1h). A direct jump was not possible, and only a roundabout walking route - without the reward in sight-led to the goal; a binary route choice was again available to the individual (Cross and Jackson 2016; Tarsitano and Jackson 1997). The spiders were often highly successful in these tasks (see "Ecological factors" section).

Several initially visible goal detour studies also made use of a four-compartment box; after spotting the goal behind a transparent/semitransparent barrier, the individual had to turn away from the barrier and head toward one of the four opaque compartments, with only two leading to the goal (chickens: Regolin et al. 1995; canaries, herring gulls and quails: Zucca et al. 2005, Fig. 1g).

Successful responses in such tasks have usually been interpreted as a result of the animal's mental representation of the non-visible goal (Vallortigara and Regolin 2002), and its use of such representations in planning the detour routes (Cross and Jackson 2016). However, no agreement has been reached on the nature of these representations, and their very existence has been questioned (Barrett 2011; Cross and Jackson 2016). For example, although some interpret the results as cases of planning where the motor response is preceded by a decision (Cross and Jackson 2016), others argue the detour behaviors emerge from step-wise and situated processes, in which the animal uses environmental and sensorimotor affordances, such as wall following or visual scanning (jumping spiders: Barrett 2011; Tarsitano 2006; octopus: Wells 1967).

Support for the embodied perspective comes from robotics, showing that robots succeed in detours not by representing the out-of-"sight" goal position, but rather by exploratory behavior using sensory feedback and the physical constraints in the environment (Walker and Miglino 1999). The setup used in this study replicated Regolin et al. (1995) who tested chickens. After initially "seeing" the goal behind the barrier, the robot had to turn its back to the reward and select from four opaque compartments, two of which led to the goal (Fig. 1g). The performance of robots was similar to the chickens' ( 22 out of 24 robots chose the right compartments), despite the lack of preprogrammed maps or other internal representations of the position of the goal (Miglino et al. 1998; Ponticorvo et al. 2007; Walker and Miglino 1999). Obviously, these results cannot tell us whether chickens use mental representations when solving the task, but only that it is in principle not necessary.

The behavior of the animal at the choice point in initially visible goal detours might be especially relevant in studying the process of deliberation and planning. At similar choice points where only one route leads to an out-of-sight goal, rats seemingly deliberate over their choices in a process called vicarious trial-and-error, where they pause and look back and forth before they chose a path (Redish 2016). During vicarious trial-and-error, the hippocampal place cells encode future outcomes (Johnson and Redish 2007) where the animal seemingly deliberates over the future alternatives. Similar neurological and behavioral investigations at choice points on initially visible goal detour tasks might shed light on the possible involvement of similar processes such as prospection in solving these detour tasks. Since vicarious trial-and-error occurs mostly when the animal faces the problem for the first time, and disappears after repeated trials (Redish 2016), it is advisable to avoid repeated trials per individual with initially visible goal detour tasks to capture this process of deliberation.

\section{Learning}

In most detour studies, individuals have been tested repeatedly, and several studies have found improvements over trials (Beniuc 1938; Boogert et al. 2011; Burghardt 1964; de Haan 1949; Fischel 1933; Lorenz 1932; Parker et al. 2005, 2012; Schiller 1949a, b; Scholes 1965; Scholes and Wheaton 1966; Smith and Litchfield 2010; Spigel 1964; Thorndike 1911; Vernouillet et al. 2016; Vlamings et al. 2010; Wallis et al. 2001; Wyrwicka 1959; however, see: Pongracz et al. 2001, 2008; Wells 1967; Zucca et al. 2005). Similarly, many studies have found animals become faster over trials in reaching the goal around the barrier, indicating yet another learning effect (Beniuc 1938; Burghardt 1964; Lockman and Adams 2001; Parker et al. 2005; Spigel 1964; Thorndike 1911; Wyrwicka 1959; but see Baragli et al. 2011 for a lack of such effect).

Accordingly, detour tasks were employed to study various learning processes. For example, studies focusing on critical learning periods compared the rate of improvement on detour tasks across different age groups in early development to explore the peak learning period (chickens: Scholes 1965, Scholes and Wheaton 1966). Other studies used detour tasks to explore learning and retention/disruption mechanisms (European green lizards: Fischel 1933; fish: Thorndike 1911; painted turtles: Spigel 1964). Research on social learning investigated whether some animals learn to solve detour problems through observing other individuals executing the detour behavior (Pongrácz et al. 2005, 2008; Wilkinson et al. 2010). 
Hull (1938) offered a model based on stimulus-response (S-R) learning in explaining the gradual improvement of detour behavior. According to this model, such an improvement happens because the excitatory potential of the direct pathway is gradually reduced due to repeated failed attempts and barrier touches. The detour behavior emerges when the excitatory strength of the indirect pathway becomes stronger than the direct pathway (Rashotte 1987; see also Wyrwicka 1959). A similar model was offered from the field of robotics to explain detour behavior based on reactive problem solving (Balkenius 1994).

In detours involving visible rewards, the recruited cognitive mechanisms might differ between when solving the problem for the first time and after repeated trials. As mentioned, Köhler believed detour behaviors, especially when performed on the first trial, signaled insightful behavior as the animal must perceive the whole problem ahead of the detour (Köhler 1925). Some detour studies, mostly initially visible goal detours, have followed a strict one trial method, to explore whether animals spontaneously solve a detour problem (Atkinson 2003; Cross and Jackson 2016; Köhler 1925; Regolin et al. 1994, 1995; Regolin and Rose 1999; Sun et al. 2010; Tarsitano and Andrew 1999; Tarsitano and Jackson 1994, 1997; Zucca et al. 2005).

Successful detours already in the first trial versus gradual increase of successes across trials are often distinguished and labeled differently: detour behavior versus detour learning (Vallortigara and Regolin 2002); spatial reasoning versus spatial learning or trial-and-error learning (Smith and Litchfield 2010; Wynne and Leguet 2004). Trial-and-error learning of the detour problem suggests a possibility that successfully solving the detour problem might arise from chance. One can imagine that after an initial frustration resulting from multiple bumps into the barrier, the animal gives up and walks away from the goal; then, once it reaches the end of the barrier, it follows the visual, acoustic or olfactory cues from the goal to finally reach it (Scholes 1965; Vallortigara and Regolin 2002). To reduce the chance that a detour occurs by chance, some studies have used modifications, mostly by offering animals multiple options (Atkinson 2003; Regolin et al. 1995; Tarsitano and Jackson 1994; Zucca et al. 2005).

Köhler suggested one should observe the movement pattern of the animal in order to distinguish whether the detour results from a thoughtful process or from chance (Köhler 1925). He argued that in the case of the "real" solution, the movement of the animal displays unity in time and space: from the starting position the animal directly goes for a reward in a single line without hesitation. Conversely, solutions resulting from chance are often characterized by the sum of disparate and discontinuous movements where the animal zigzags in front of the barrier; and only once it has seen the reward from outside the barrier its movements become continuous toward the reward. Such a mechanism based on chance was also central for the S-R theories in explaining the initial solution to the detour problem (Hull 1938; Rashotte 1987).

However, seemingly contradicting the behavioristic stance (Hull 1938), learning effects do not only come gradually, but sometimes also rapidly after the first successful detour solution (Beniuc 1938; Regolin et al. 1995; Regolin and Rose 1999; Siniscalchi et al. 2013). Regolin et al. (1995) claimed that instead of gradual learning, rapid improvement may emerge from overcoming stress responses due to being tested in a novel environment. Besides, learning cannot explain all successful detour performances in studies that have used repeated trials as some species did perform well already from the initial trials (Bray et al. 2014; Kabadayi et al. 2016; MacLean et al. 2014; Marshall-Pescini et al. 2015; Smith and Litchfield 2010).

\section{Task switching}

On the assumption that some detour tasks measure inhibition, swift improvement of the performance across trials might be inconsistent with findings from other inhibition tasks where no or very little improvement over trials is found (Berkman et al. 2014; Zelazo et al. 1996). Moreover, in contrast to other motor inhibition tasks, individuals often reach and maintain a ceiling level of perfect accuracy in detour tasks after repeated testing (song sparrows: Boogert et al. 2011; parrots: Kabadayi et al. 2017a). In classical behavioral inhibition tasks, subjects know the task rules but are unable to follow them to achieve and preserve peak performance even after being tested repeatedly, because the task presents additional inhibitory challenges, often due to task switching. For example, on certain trials subjects have to inhibit an already initiated response (stop-signal task) or a response that has been repeated previously (go/no-go task). However, one can achieve and preserve peak performance in detour tasks by following the same strategy that proved to be effective in the previous trial(s). Neurological evidence suggests the detour task may cease to measure inhibition after the task is acquired and perfect accuracy is reached (Walker et al. 2006). This suggests after repeated trials with detour tasks, the knowing/acting mismatch weakens, and the visual reward behind the barrier no longer exerts a strong pull on direct reaching behavior.

Offering shortcuts on certain trials might test whether the detour response becomes habitual after repeated trials (Verbruggen et al. 2014). This idea was already implemented over 100 years ago by Thorndike, who found if chickens used a detour path in around 75-80 trials, they tended to ignore shortcuts that were later made available (Thorndike 1911). Similarly, dogs appear to have difficulty 
using shortcuts after detouring over repeated trials. They tend to cling onto the detour response instead of taking the shorter path, suggesting functional fixedness (Pongracz et al. 2003a, b). The tendency of repeating the old-but not the most appropriate-response is especially pronounced if the dogs learn the detour from a human, perhaps as a result of domestication (Pongracz et al. 2003a, b). Likewise, dogs commit preservative errors by sticking to the previously reinforced detour despite an explicit change in the detour setup that requires a different response (Clarke et al. 1951; Hobhouse 1901; Osthaus et al. 2010).

Shortcuts could also be used in a task-switching context and increase the inhibitory requirements by adding a learned component that must be inhibited (Monsell 2003). The general setup in the few studies that have used this taskswitching component is the offering of a shortcut through an opening in the barrier; and after the animals have used the shortcut over repeated trials, removing the shortcut thereby forces the animals to take a detour. Whereas using the shortcut significantly deteriorates the subsequent detour response for dogs (Marshall-Pescini et al. 2015; Pongracz et al. 2003a, b), dingoes show pronounced task-switching skills as they detour equally efficiently around the barrier after the shortcut is no longer available (Smith and Litchfield 2010). Similarly, squirrel monkeys have more difficulties in making detours after the shortcut is blocked (Lyons et al. 2000; Parker et al. 2005, 2012), suggesting a cost from task switching (Monsell 2003). Implementing shortcuts in detour setup prevents a ceiling effect of perfect accuracy (Jentsch et al. 2000; Parker et al. 2005, 2012). Transparent detour apparatuses with only one opening (Fig. 1e) are suitable for such task-switching problems as one can change the open side that faces the subject across the trials (Lyons et al. 2000; Parker et al. 2012).

\section{Functional generalization}

Are different versions of detour tasks understood by animals in similar ways because they share the same underlying principle? Such functional generalization would allow an animal to take into account higher-order functional aspects of a detour problem and ignore irrelevant perceptual features (Call 2013; Jacobs and Osvath 2015).

Evidence suggests that perceptual features might considerably affect detour performance in many species (see Table 2). For example, children found it more challenging to make locomotor detours than reaching detours around transparent barriers (Lockman and Adams 2001). Similarly, a study found no correlation between performances of dogs and wolves in equivalent locomotor and reaching detour tasks (Marshall-Pescini et al. 2015). The orientation of the barrier also affects the success of chickens, dogs and goats (Nawroth et al. 2016; Pongracz et al. 2001; Regolin et al.
1994). With V-shaped barriers, both dogs and goats were more successful in outward (subject begins inside the vertex of V) than inward (subject begins outside the vertex of V) detours (Nawroth et al. 2016; Pongracz et al. 2001, Table 2, Fig. 1b).

The lack of generalization of different detour problems can also be explained from an action-perception perspective where the subjects, through their interactions with the barriers, obtain information about the specific affordances and possibilities for action, and they are not merely reacting to reward visibility (Lockman and Adams 2001; Thelen et al. 2001). However, this does not mean all species lack functional generalization when it comes to detour tasks. Such generalization might help when faced with a transparent barrier after training on an identical but opaque barrier, as is often done in many studies (e.g., MacLean et al. 2014; Wallis et al. 2001). Those species that are more efficient in perceiving the functional similarity between opaque and transparent barriers should find it easier to detour around the transparent barrier. In primates for example, the lateral prefrontal cortex seems to mediate this ability of functional generalization and task transfer between opaque and transparent barriers (Wallis et al. 2001, see "Neurological underpinnings of detour behaviors" section).

\section{Ecological, neurological and developmental underpinnings of detour behaviors}

\section{Ecological factors}

As many species face problems similar to the detour paradigm in their environments, detour tests likely often reflect ecologically relevant situations, and detour problems might be more ecologically meaningful for some species compared to others. Various comparative studies using detour problems attributed the results partly to the ecology of the tested species (birds: Miller and Tallarico 1974; Zucca et al. 2005; canines: Marshall-Pescini et al. 2015; Pongracz et al. 2001; Smith and Litchfield 2010; great apes: Vlamings et al. 2010; jumping spiders: Cross and Jackson 2016; Tarsitano and Jackson 1994; monkeys: Amici et al. 2008; reptiles: Burghardt 1977).

For example, the perception of the task features might differ between species due to their ecology. Dogs find it harder to take inward detours rather than outward detours around $\mathrm{V}$-shaped barriers, probably because they tend to avoid constricted spaces (Pongracz et al. 2001). Analogously, how obstacles are perceived may differ between aerial and terrestrial species: vertical obstacles may be more ecologically meaningful for flying species compared to earth bound ones (Lorenz 1971). This may explain why chickens, which are 
poor flyers, performed worse on detours around barriers with vertical bars than with horizontal ones (Regolin et al. 1994; Vallortigara and Regolin 2002), whereas herring gulls displayed an opposite pattern (Zucca et al. 2005). Similarly, Zucca et al. (2005) found that canaries performed markedly worse in a detour problem (Fig. 1g) compared to quails and young herring gulls. The authors suggested the adaptation to terrestrial or aerial habitats could explain this difference: whereas in their natural environment canaries could avoid the detour problem simply by flying, the detour problem was ecologically meaningful for ground-living quails and young herring gulls that use walking as the main mode of locomotion.

Similarly, detour problems might be more ecologically meaningful for predators compared to prey species, as their pursuit of prey often involves detours around obstacles (Lorenz 1932). For example, jumping spiders performed remarkably well in many detour problems (Cross and Jackson 2016); and this was attributed to their ecology as in the wild they navigate complex three-dimensional environments when searching for prey, using their well-developed visual system (Tarsitano 2006).

In general, certain skills, that are adaptive within a certain ecological niche, might prove more useful than others in solving various detour problems. Thus, ecological factors must be addressed both in the task's design and in the interpretation of the results. Some authors have given central importance to such ecological factors. For example, Burghardt (1977) asserted that detour behaviors are as much a result of the dominant sense, and cue relevance and species ecology, as of "intelligence." However, hardwired predispositions due to species-specific ecological factors cannot solely explain detour success, as there are learning effects and individual variation within species (Dettmer et al. 2015; Frank and Frank 1982; Juszczak and Miller 2016; Köhler 1925). Due to these differences, an average success rate in the task is often not sufficient in inter-species comparisons; instead, a variance of the species-specific success rates may be more informative.

Others have taken a more integrated approach, using detour tasks across species to measure the socio-ecological correlates of certain cognitive skills. For example, Vlamings et al. (2010) found orangutans outperformed chimpanzees, bonobos and gorillas in a detour task called the swing-door task, which is considered to test for inhibition (Fig. 1d). The authors partly attributed the high inhibitory skills of orangutans to the reduced food competition among group mates compared to other great ape species. Similarly, Amici et al. (2008) used two detour tasks-the swing-door task and Plexiglas-hole task (Fig. 1c) — as parts of a task battery measuring inhibitory control in seven species of primates, and found that the species living in more dynamic and fluid social environments (fission-fusion societies) outperformed those having more cohesive group structures. The authors concluded primates living in more complex social groups often require inhibition of inappropriate prepotent responses in a dynamic social environment, and this partly explains why they performed better in detour tasks.

Attempts to find tasks that could be applicable to wide range of species have led to a simplification of the detour setup. More recently, a detour task was designed utilizing a hollow transparent cylinder and it was named "the cylinder task" (Bray et al. 2014). This task requires inhibition of a direct reach for the reward placed centrally inside a hollow transparent cylinder, and an execution of a detour through one of the side openings instead (Fig. 1a). Each subject receives training on an opaque cylinder before being tested on a transparent, but otherwise identical, cylinder. The training ensures the subjects learn the correct detour solution; then, the subsequent errors in the transparent condition may be attributed to the inhibition failure (Santos et al. 1999), consistent with the idea of the existence of a knowing/acting mismatch. The cylinder task was recently administered to 36 different species-29 mammal and seven bird species-in order to study the evolution of motor inhibition (MacLean et al. 2014). This study found that the great apes were the most successful on the cylinder task of all the species tested and that absolute brain size significantly correlated with the task performance (see "Neurological underpinnings of detour behaviors" section).

\section{Neurological underpinnings of detour behaviors}

Most neurocognitive studies have relied on induced lesions in primate brains to find correlations between various brain regions and the execution of effective detour responses. The object-retrieval task, a detour reaching task around a transparent cubicle (Fig. 1e), is the most popular detour task used in these lesion studies, and successful performance in this task has been interpreted as an expression of inhibitory control. The lesion studies targeted the prefrontal cortex, given its role in supporting inhibitory processes (Diamond 1990).

Rhesus monkeys with dorsolateral prefrontal cortex ablations and marmoset monkeys with joint lesions of orbitofrontal and lateral prefrontal cortex had difficulties with detouring transparent barriers (Diamond and GoldmanRakic 1985; Dias et al. 1996; Moll and Kuypers 1977). Other studies on African green monkeys have suggested low dopamine levels in the striatum and the prefrontal cortex, as well as serotonin depletions in orbitofrontal cortex, deteriorate the detour performance around transparent barriers (Jentsch et al. 1997, 1999a, b, 2000; Taylor et al. 1990a, b; Walker et al. 2006).

A study on marmoset monkeys suggested two separate and dissociable systems play a role for detours around transparent barriers (Wallis et al. 2001). Orbitofrontal cortex 
lesioned marmosets performed poorly compared to controls in detours around a transparent box. But after extensive training with an identical but an opaque box, the lesioned monkeys overcame their problems. In contrast, lateral prefrontal cortex lesioned monkeys had problems transferring the detour behavior they learned in the opaque box to the transparent box. This suggests at least two different brain areas facilitate detours around transparent barriers: one for motor inhibition (the orbitofrontal cortex) and another for task transfer between the opaque and the transparent barrier (the lateral prefrontal cortex). This study also provides a neurological explanation for the common behavioral finding that experience with opaque barriers improve detours around transparent, but otherwise identical, barriers (Juszczak and Miller 2016; Santos et al. 1999).

A recent large-scale comparative study testing 36 species, 29 mammal and 7 bird species found absolute brain size strongly predicted detour performance on the cylinder task (Fig. 1a), with great apes as the best performers (MacLean et al. 2014). This conclusion was soon challenged when three corvid species (ravens, New Caledonian crows and jackdaws) showed scores similar to great apes on the cylinder task, despite having vastly smaller absolute brains sizes (Kabadayi et al. 2016). However, corvids have much greater neural densities than primates (Olkowicz et al. 2016), and it has been suggested that total number of pallial neurons is a better predictor of cognitive ability-including cylinder task performance - than absolute brain size (Herculano-Houzel 2017). But parrots, despite having similarly high numbers of pallial neurons, performed poorly on the cylinder task (Kabadayi et al. 2017a). Such discrepant findings suggest the level of analyses should focus on specific brain regions rather than the whole pallium. As mentioned, in primates, detours around the transparent barriers are mediated by prefrontal regions. In birds, the associative brain area called nidopallium caudolateral (NCL) is an obvious candidate for a similar function. The NCL functions analogously to the mammalian prefrontal cortex (Güntürkün 2005) and mediates other executive processes such as working memory as well as motor inhibition (Kalt et al. 1999; Veit and Nieder 2013).

\section{The development of detour behaviors}

Comparative developmental studies using detour tasks may also provide insights into the evolution of cognition. Cognitive developmental research investigates the emergence of adaptive systems from the various combinations of cognitive building blocks during development (Gómez 2005). Development is a key evolutionary mechanism, and developmental investigations can complement comparative studies in order to reach a better understanding of cognitive evolution (Rosati et al. 2014). For example, they can reveal if different species attain similar cognitive skills using similar or different building blocks (Osvath et al. 2014). Despite this potential importance, there are few comparative developmental studies, with rhesus monkeys and ravens representing the only non-human species tested longitudinally through development (Diamond 1990; Kabadayi et al. 2017b).

Detour problems with transparent or fence barriers have been used to study the development of inhibitory skills and motor control in human infants (Bojczyk and Corbetta 2004; Diamond 1990; Lockman 1984; Lockman and Adams 2001; Piaget 1954) and rhesus monkey infants (Diamond and Goldman-Rakic 1986). Human infants exhibit a clear developmental progression between the sixth and the 12th month of life in detouring transparent barriers (Diamond 1981; Diamond and Gilbert 1989), and similar developmental trajectory has been found in infant rhesus monkeys between the first and the fourth month (Diamond and Goldman-Rakic 1986). During a certain period, both human and rhesus monkey infants perform better with an opaque barrier compared to an identical but transparent one (Diamond 1981, 1990; Lockman 1984). This "opaque advantage" during a certain developmental period suggests the problem with detours around transparent barriers is one of inhibition. The gradual overcoming of the difficulty of detouring around transparent barriers has thus been attributed to the development of executive functions and to the maturation of prefrontal cortex (Diamond 1990, 1991; however, see below for a different view from the perspective of motor control).

Raven chicks have similar difficulties during development in inhibiting a direct reach for a reward behind a transparent barrier, but they overcome this difficulty and succeed in the cylinder task when they are around 10 weeks old (Kabadayi et al. 2017b). Before the 10th week, and after they attain object permanence, they perform better on opaque barriers than transparent ones. Their detour performance on a fence barrier is better than on a fully transparent barrier. This suggests reduced reward visibility makes it easier to inhibit motor responses (for a similar finding in human infants: Lockman and Adams 2001; Noland 2008).

Developmental studies can also demarcate the relative contributions of motor experience and cognitive maturation in solving detour problems. For example, Diamond (1988) found human infants tested longitudinally (tested every second week) succeeded on the detour reaching task around 2-4 weeks earlier than infants in the cross-sectional group [for a similar finding in ravens see Kabadayi et al. (2017b)]. This suggests repeated motor experience with the task helps infants solve the task earlier, and the successful detours develop not solely from a task-independent inhibitory maturation, but also from an interaction of various processes such as sensorimotor experience with the barrier as well as motor coordination (Williams et al. 2015). 


\section{Conclusion and future directions}

There are numerous advantages of using the detour paradigm. It is easy to administer and often ecologically meaningful: many animals face situations in their natural environment where various obstacles block the shortest path to the goal. However, there is surprisingly little agreement on the cognitive requirements for successful detours. Inhibitory control is a common interpretation of continuously visible goal detours; however, rule learning and functional generalization/task transfer are other cognitive skills likely involved in solving detour problems. Instead of comparing the average scores obtained over a fixed number of trials on detour tasks, investigating how species obtain those scores might yield better understanding on these other cognitive processes involved in solving the task and hence lead to a more robust comparison of the cognitive skills between species (Güntürkün et al. 2017).

For example, increasing the number of training trials received with an opaque cylinder might shed light to the relative contribution of functional generalization to the cylinder task performance. Similarly, measuring the change in latency to obtain a reward behind a barrier might reveal an operant/rule learning component. Inserting shortcuts into the detour setup can measure whether the detour response has become habitual after repeated trials, and implementing switches between shortcuts and detours may measure task-switching skills. Systematically targeting these different cognitive processes by controls and modifications in detour setups can allow robust quantification of cognitive traits, which would lead to meaningful intra-and inter-species comparisons (Thornton et al. 2014).

The executive function interpretation of the detour problem is based on the knowing/acting mismatch: the subject must have the necessary physical knowledge to solve the detour problem, and yet it cannot reflect this knowledge in action because the visible reward behind the barrier creates a lure and the subject acts impulsively by attempting a direct reach. The inhibitory faculty thus liberates the already existing knowledge from the intrusion of impulsive tendencies. Thus, studies focusing on inhibition should ensure the animals tested know the impenetrability of the transparent barrier. This means they should have sufficient experience with transparent objects before being tested with transparent barrier detour tasks. This is especially important given that transparent objects are highly artificial (animals rarely face transparent barriers in their natural environment) and present conflicting visual/tactile information. Inhibition tasks often infer costs when choosing the immediate gratification/acting impulsively. However, some detour tasks-such as the cylinder task-do not infer a major cost to animals when they make a contact with the barrier in an attempt to directly reach for the reward. In order to make inhibitory failures costlier, one can modify the detour setup, e.g., a direct contact to the barrier makes the reward unavailable, as in the swing-door task (Fig. 1d, also see: Hughes and Russell 1993).

When it comes to initially visible goal detours, there is a similar dispute concerning the precise nature of the representations necessary to solve such tasks. The core question depends on whether animals plan their detour routes at the beginning of the task when they can see the reward, and later use those representations when choosing the correct pathway among alternatives, when the reward goes out of sight. Controlling for factors such as landmark use and path integration is helpful to test this question. Another promising avenue might be to observe the behavior, and possibly the brain, at the choice point: a vicarious trialand-error behavior and an accompanying future-encoding place cell activity might reflect a process of deliberation and planning (Redish 2016). First trials are of importance for such observations because the deliberation process tends to disappear after repeated trials (Redish 2016).

Neurological correlates of detour behavior might provide useful information on the cognitive mechanisms measured by detour tasks. For example, neuropsychological studies focused on specific brain regions suggested that for primates, visible goal detour tasks measure not only inhibition, but also functional generalization (Wallis et al. 2001); and the detour task may stop measuring inhibition once the ceiling level of perfect accuracy is reached (Walker et al. 2006). Consistently, future comparative studies should focus on specific brain regions, instead of broad correlations such as absolute/relative brain size and the total number of pallial neurons.

Comparative developmental studies can provide useful tools to approach cognitive evolution from an ontogenical perspective, i.e., how cognition emerges from various constellations of cognitive building blocks (Gómez 2005). Thus, developmental comparisons may reveal novel patterns that cannot be uncovered by comparing adult performances (Rosati et al. 2014). Similar developmental patterns between different species suggest a similarly constructed cognitive skill, whereas differences in pattern may reveal a different architecture, which can explain differences in mature cognition. There are only few developmental studies on detour behaviors. Expanding such developmental studies would be promising in answering whether the pace and pattern of development share similarities across lineages (Rosati et al. 2014).

We have pointed toward various contextual factors that affect detour performances (Table 2). Comparative studies should take into account such factors for robust comparisons. Simplifying the task is a convenient attempt in this direction, but there are still numerous factors that should 
be controlled for, such as the previous experience with transparency, motivation, size and material of the barrier, age and sensorimotor capability of the animal. Since taskspecific factors may favor certain species at the expense of the others, avoiding single tasks and using detour task batteries might lead to more robust comparisons.

Acknowledgements We thank Megan Lambert and Ivo Jacobs for commenting on the manuscript. This work was funded by the Swedish Research Council Grants 2012-1235 and 2014-6402, later conjoined with Marie Skłodowska Curie Actions, Cofund, INCA 600398.

\section{Compliance with ethical standards}

Conflict of interest The authors declare no conflict of interest.

Open Access This article is distributed under the terms of the Creative Commons Attribution 4.0 International License (http://creativecommons.org/licenses/by/4.0/), which permits unrestricted use, distribution, and reproduction in any medium, provided you give appropriate credit to the original author(s) and the source, provide a link to the Creative Commons license, and indicate if changes were made.

\section{References}

Amici F, Aureli F, Call J (2008) Fission-fusion dynamics, behavioral flexibility, and inhibitory control in primates. Curr Biol 18:14151419. https://doi.org/10.1016/j.cub.2008.08.020

Atkinson JW (2003) Foraging strategy switch in detour behavior of the land snail Anguispira alternata (Say). Invertebr Biol 122:326333. https://doi.org/10.1111/j.1744-7410.2003.tb00097.x

Balkenius C (1994) Biological learning and artificial intelligence. LUCS Publication Series, 30

Baragli P, Vitale V, Paoletti E, Sighieri C, Reddon AR (2011) Detour behaviour in horses (Equus caballus). J Ethol 29:227-234. https://doi.org/10.1007/s10164-010-0246-9

Barrett L (2011) Beyond the brain: how body and environment shape animal and human minds. Princeton University Press, Princeton

Bell MA, Fox NA (1992) The relations between frontal brain electrical activity and cognitive development during infancy. Child Dev 63:1142-1163. https://doi.org/10.2307/1131523

Beniuc M (1938) The roundabout path of the fighting fish (Betta splendens). Proc Zool Soc Lond 108:403

Berkman ET, Kahn LE, Merchant JS (2014) Training-induced changes in inhibitory control network activity. J Neurosci 34:149-157. https://doi.org/10.1523/JNeurosci.3564-13,2014

Bisazza A, Pignatti R, Vallortigara G (1997) Laterality in detour behaviour: interspecific variation in poeciliid fish. Anim Behav 54:1273-1281. https://doi.org/10.1006/anbe.1997.0522

Bisazza A, Facchin L, Pignatti R, Vallortigara G (1998) Lateralization of detour behaviour in poeciliid fish: the effect of species, gender and sexual motivation. Behav Brain Res 91:157-164. https://doi. org/10.1016/S0166-4328(97)00114-9

Bojczyk KE, Corbetta D (2004) Object retrieval in the 1st year of life: learning effects of task exposure and box transparency. Dev Psychol 40:54. https://doi.org/10.1037/0012-1649.40.1.54

Boogert NJ, Anderson RC, Peters S, Searcy WA, Nowicki S (2011) Song repertoire size in male song sparrows correlates with detour reaching, but not with other cognitive measures. Anim Behav 81:1209-1216. https://doi.org/10.1016/j.anbehav.2011.03.004
Bray EE, MacLean EL, Hare BA (2014) Context specificity of inhibitory control in dogs. Anim Cogn 17:15-31. https://doi. org/10.1007/s10071-013-0633-z

Bray EE, MacLean EL, Hare BA (2015) Increasing arousal enhances inhibitory control in calm but not excitable dogs. Anim Cogn 18:1317-1329. https://doi.org/10.1007/s10071-015-0901-1

Brucks D, Marshall-Pescini S, Wallis LJ, Huber L, Range F (2017) Measures of dogs' inhibitory control abilities do not correlate across tasks. Front Psychol 8:849. https://doi.org/10.3389/ fpsyg.2017.00849

Burghardt G (1964) Effects of prey size and movement on the feeding behavior of the lizards Anolis carolinensis and Eumeces fasciatus. Copeia 1964:576-578

Burghardt GM (1977) Learning processes in reptiles. Biol Reptilia $7: 555-681$

Call J (2013) Three ingredients for becoming a creative tool user. In: Sanz CM, Call J, Boesch C (eds) Tool use in animals: cognition and ecology. Cambridge University Press, Cambridge, pp 3-20

Cannon CE, Puri V, Vivian JA, Egbertson MS, Eddins D, Uslaner JM (2013) The nicotinic $\alpha 7$ receptor agonist GTS-21 improves cognitive performance in ketamine impaired rhesus monkeys. Neuropharmacology 64:191-196. https://doi.org/10.1016/j. neuropharm.2012.05.003

Chapuis N (1987) Detour and shortcut abilities in several species of mammals. In: Ellen P, Thinus-Blanc C (eds) Cognitive processes and spatial orientation in animal and man. NATO ASI Series. Springer, Dordrecht, pp 97-106

Chapuis N, Thinus-Blanc C, Poucet B (1983) Dissociation of mechanisms involved in dogs' oriented displacements. Q J Exp Psychol 35:213-219. https://doi.org/10.1080/14640748308400906

Clarke R, Heron W, Fetherstonhaugh M, Forgays D, Hebb D (1951) Individual differences in dogs: preliminary report on the effects of early experience. Can J Exp Psychol 5:150-156

Collett T (1982) Do toads plan routes? A study of the detour behaviour of Bufo viridis. J Comp Physiol 146:261-271. https://doi. org/10.1007/BF00610246

Cross FR, Jackson RR (2016) The execution of planned detours by spider-eating predators. J Exp Anal Behav 105:194-210. https:// doi.org/10.1002/jeab.189

Dalla Costa E, Allegrini M, Cerri E, Minero M (2013) Social learning in horses: Does the demonstration of a conspecific affect the ability to solve a detour task? J Vet Behav 8:e5. https://doi. org/10.1016/j.jveb.2012.12.012

de Haan JAB (1949) Animal psychology: its nature and its problems, vol 15. Hutchinson's University Library, Oxford

Dettmer AM, Murphy AM, Suomi SJ (2015) Development of a cognitive testing apparatus for socially housed mother-peer-reared infant rhesus monkeys. Dev Psychobiol 57:349-355. https://doi. org/10.1002/dev.21285

Diamond A (1981) Retrieval of an object from an open box: the development of visual-tactile control of reaching in the first year of life. SRCD Abstr 3:78

Diamond A (1988) Differences between adult and infant cognition: Is the crucial variable presence or absence of language? In: Weiskrantz L (ed) Thought without language. Clarendon Press/Oxford University Press, New York, pp 337-370

Diamond A (1990) Developmental time course in human infants and infant monkeys, and the neural bases of inhibitory control in reaching. Ann NY Acad Sci 608:637-676. https://doi. org/10.1111/j.1749-6632.1990.tb48913.x

Diamond A (1991) Neuropsychological insights into the meaning of object concept. In: Carey S, Gelman R (eds) The epigenesis of mind: essays on biology and cognition. Lawrence Erlbaum, Hillsdale, pp 67-110

Diamond A (2013) Executive functions. Ann Rev Psychol 64:135-168. https://doi.org/10.1146/annurev-psych-113011-143750 
Diamond A, Gilbert J (1989) Development as progressive inhibitory control of action: retrieval of a contiguous object. Cogn Dev 4:223-249. https://doi.org/10.1016/0885-2014(89)90007-5

Diamond A, Goldman-Rakic P (1985) Evidence for involvement of prefrontal cortex in cognitive changes during the first year of life: comparison of performance of human infants and rhesus monkeys on a detour task with transparent barrier. Soc Neurosci Abstr 11:832

Diamond A, Goldman-Rakic P (1986) Comparative development in human infants and infant rhesus monkeys of cognitive functions that depend on prefrontal cortex. Soc Neurosci Abstr 12:742

Diamond A, Zola-Morgan S, Squire LR (1989) Successful performance by monkeys with lesions of the hippocampal formation on $\mathrm{AB}$ and object retrieval, two tasks that mark developmental changes in human infants. Behav Neurosci 103:526-537. https://doi. org/10.1037//0735-7044.103.3.526

Dias R, Robbins T, Roberts A (1996) Primate analogue of the Wisconsin Card Sorting Test: effects of excitotoxic lesions of the prefrontal cortex in the marmoset. Behav Neurosci 110:872-886. https://doi.org/10.1037//0735-7044.110.5.872

Eddins D, Hamill TG, Puri V et al (2014) The relationship between glycine transporter 1 occupancy and the effects of the glycine transporter 1 inhibitor RG1678 or ORG25935 on object retrieval performance in scopolamine impaired rhesus monkey. Psychopharmacology 231:511-519. https://doi.org/10.1007/ s00213-013-3260-0

Edgin JO, Inder TE, Anderson PJ, Hood KM, Clark CA, Woodward LJ (2008) Executive functioning in preschool children born very preterm: relationship with early white matter pathology. J Int Neuropsychol Soc 14:90-101. https://doi.org/10.1017/ S1355617708080053

Elsworth JD, Groman SM, Jentsch JD et al (2012) Asenapine effects on cognitive and monoamine dysfunction elicited by subchronic phencyclidine administration. Neuropharmacology 62:14421452. https://doi.org/10.1016/j.neuropharm.2011.08.026

Facchin L, Bisazza A, Vallortigara G (1999) What causes lateralization of detour behavior in fish? Evidence for asymmetries in eye use. Behav Brain Res 103:229-234. https://doi.org/10.1016/ s0166-4328(99)00043-1

Fagnani J, Barrera G, Carballo F, Bentosela M (2016) Is previous experience important for inhibitory control? A comparison between shelter and pet dogs in A-not-B and cylinder tasks. Anim Cogn 19:1165-1172. https://doi.org/10.1007/s10071-016-1024-z

Fischel W (1933) Über bewahrende und wirkende Gedächtnisleistung. Biol Zbl 53:449-471

Frank H, Frank MG (1982) Comparison of problem-solving performance in six-week-old wolves and dogs. Anim Behav 30:95-98. https://doi.org/10.1016/s0003-3472(82)80241-8

Gómez JC (2005) Species comparative studies and cognitive development. Trends Cogn Sci 9:118-125. https://doi.org/10.1016/j. tics.2005.01

Gray RA, Wilcox KM, Zink MC, Weed MR (2006) Impaired performance on the object retrieval-detour test of executive function in the SIV/macaque model of AIDS. AIDS Res Hum Retrovir 22:1031-1035. https://doi.org/10.1089/aid.2006.22.1031

Güntürkün O (2005) The avian 'prefrontal cortex'and cognition. Curr Opin Neurobiol 15:686-693. https://doi.org/10.1016/j. conb.2005.10.003

Güntürkün O, Ströckens F, Scarf D, Colombo M (2017) Apes, feathered apes, and pigeons: differences and similarities. Curr Opin Behav Sci 16:35-40. https://doi.org/10.1016/j.cobeha.2017.03.003

Herculano-Houzel S (2017) Numbers of neurons as biological correlates of cognitive capability. Curr Opin Behav Sci 16:1-7. https:// doi.org/10.1016/j.cobeha.2017.02.004

Hobhouse LT (1901) Mind in evolution. The Macmillan Company, New York
Hughes C, Russell J (1993) Autistic children's difficulty with mental disengagement from an object: its implications for theories of autism. Dev Psychol 29:498-510. https://doi. org/10.1037//0012-1649.29.3.498

Hughes C, Dunn J, White A (1998) Trick or treat? Uneven understanding of mind and emotion and executive dysfunction in "Hard-tomanage" preschoolers. J Child Psychol Psychiatry 39:981-994. https://doi.org/10.1111/1469-7610.00401

Hull CL (1938) The goal-gradient hypothesis applied to some 'fieldforce' problems in the behavior of young children. Psychol Rev 45:271-299

Ingle DJ (1971) Prey-catching behavior of anurans toward moving and stationary objects. Vision Res 11:447-456. https://doi. org/10.1016/0042-6989(71)90057-5

Jacobs IF, Osvath M (2015) The string-pulling paradigm in comparative psychology. J Comp Psychol 129:89-120. https://doi. org/10.1037/a0038746

Jentsch JD, Redmond DE, Elsworth JD, Taylor JR, Youngren KD, Roth RH (1997) Enduring cognitive deficits and cortical dopamine dysfunction in monkeys after long-term administration of phencyclidine. Science 277:953-955. https://doi.org/10.1126/ science.277.5328.953

Jentsch J, Taylor J, Elsworth J, Redmond D, Roth R (1999a) Altered frontal cortical dopaminergic transmission in monkeys after subchronic phencyclidine exposure: involvement in frontostriatal cognitive deficits. Neurosci 90:823-832. https://doi. org/10.1016/S0306-4522(98)00481-3

Jentsch JD, Taylor JR, Redmond DE Jr, Elsworth JD, Youngren KD, Roth RH (1999b) Dopamine D4 receptor antagonist reversal of subchronic phencyclidine-induced object retrieval/detour deficits in monkeys. Psychopharmacol 142:78-84. https://doi. org/10.1007/s002130050865

Jentsch JD, Roth RH, Taylor JR (2000) Object retrieval/detour deficits in monkeys produced by prior subchronic phencyclidine administration: evidence for cognitive impulsivity. Biol Psychiatry 48:415-424. https://doi.org/10.1016/ s0006-3223(00)00926-4

Johnson A, Redish AD (2007) Neural ensembles in CA3 transiently encode paths forward of the animal at a decision point. J Neurosci 27:12176-12189. https://doi.org/10.1523/ JNeurosci.3761-07,2007

Junghans AF, Sterck EHM, Overduin de Vries A, Evers C, De Ridder DTD (2016) Defying food-how distance determines monkeys' ability to inhibit reaching for food. Front Psychol. https://doi. org/10.3389/fpsyg.2016.00158

Juszczak GR, Miller M (2016) Detour behavior of mice trained with transparent, semitransparent and opaque barriers. PLoS ONE 11:e0162018. https://doi.org/10.1371/journal.pone.0162018

Kabadayi C, Taylor LA, von Bayern AM, Osvath M (2016) Ravens, New Caledonian crows and jackdaws parallel great apes in motor self-regulation despite smaller brains. R Soc Open Sci 3:160104. https://doi.org/10.1098/rsos.160104

Kabadayi C, Krasheninnikova A, O’Neill L, van de Weijer J, Osvath M, von Bayern AM (2017a) Are parrots poor at motor self-regulation or is the cylinder task poor at measuring it? Anim Cogn. https://doi.org/10.1007/s10071-017-1131-5

Kabadayi C, Jacobs I, Osvath M (2017b) The Development of motor selfregulation in ravens. Front Psychol. https://doi.org/10.3389/ fpsyg.2017.02100

Kalt T, Diekamp B, Güntürkün O (1999) Single unit activity during a Go/NoGo task in the "prefrontal cortex" of pigeons. Brain Res 839:263-278. https://doi.org/10.1016/S0006-8993(99)01727-8

Kemp ME (2016) Cognition and problem solving using detour reaching and novel object tasks in the Budgerigar. Distinction Papers 29. http://digitalcommons.otterbein.edu/stu_dist/29 
Kiker J, Siegel P, Hinkelmann K (1976) Genetic analysis of behaviors related to the solution of a detour learning task. Behav Genet 6:315-326. https://doi.org/10.1007/bf01065727

Köhler W (1925) The mentality of apes Translated from the second revised edition by Ella Winter, B Sc London: Kegan Paul, Trench, Trubner \& Co, Ltd

Lakshminarayanan V, Santos LR (2009) Cognitive preconditions for responses to fairness: an object retrieval task in capuchin monkeys (Cebus apella). J Neurosci Psychol Econ 2:12-20. https:// doi.org/10.1037/a001-5457

Lewin K (1933) Vectors, cognitive processes, and Mr. Tolman's criticism. J Gen Psychol 8:318-345

Lock A, Collett T (1979) A toad's devious approach to its prey: a study of some complex uses of depth vision. J Comp Physiol 131:179-189. https://doi.org/10.1007/bf00619078

Lockman JJ (1984) The development of detour ability during infancy. Child Dev 55:482-491. https://doi.org/10.2307/1129959

Lockman JJ, Adams CD (2001) Going around transparent and gridlike barriers: detour ability as a perception-action skill. Dev Sci 4:463-471. https://doi.org/10.1111/1467-7687.00188

Lorenz K (1932) Betrachtungen über das Erkennen der arteigenen Triebhandlungen der Vögel. J für Ornithologie 80:50-98

Lorenz K (1971) Studies in animal and human behavior (vol II). Harvard University Press, Cambridge

Lucon-Xiccato T, Gatto E, Bisazza A (2017) Fish perform like mammals and birds in inhibitory motor control tasks. Nat Sci Rep 7:13144. https://doi.org/10.1038/s41598-017-13447-4

Lustig A, Ketter-Katz H, Katzir G (2013) Lateralization of visually guided detour behaviour in the common chameleon, Chamaeleo chameleon, a reptile with highly independent eye movements. Behav Process 100:110-115. https://doi.org/10.1016/j. beproc.2013.08.002

Lyons DM, Lopez JM, Yang C, Schatzberg AF (2000) Stress-level cortisol treatment impairs inhibitory control of behavior in monkeys. J Neurosci 20:7816-7821

MacLean EL et al (2014) The evolution of self-control. Proc Natl Acad Sci USA 111:E2140-E2148. https://doi.org/10.1073/ pnas. 1323533111

Marshall-Pescini S, Virányi Z, Range F (2015) The effect of domestication on inhibitory control: wolves and dogs compared. PLoS ONE 10:e0118469. https://doi.org/10.1371/journal. pone. 0118469

Matthews A, Ellis AE, Nelson CA (1996) Development of preterm and full-term infant ability on $\mathrm{AB}$, recall memory, transparent barrier detour, and means-end tasks. Child Dev 67:2658-2676. https:// doi.org/10.2307/1131745

Miglino O, Denaro D, Tascini G, Parisi D (1998) Detour behavior in evolving robots: Are internal representations necessary? In: Husbands P, Meyer JA (eds) Evolutionary robotics, first European Workshop, EvoRobot 98. Springer, Berlin, pp 59-70. https://doi. org/10.1007/3-540-64957-364

Miller DB, Tallarico RB (1974) On the correlation of brain size and problem-solving behavior of ring doves and pigeons. Brain Behav Evol 10:265-273. https://doi.org/10.1159/000124318

Moll L, Kuypers H (1977) Premotor cortical ablations in monkeys: contralateral changes in visually guided reaching behavior. Science 198:317-319. https://doi.org/10.1126/science.410103

Monsell S (2003) Task switching. Trends Cogn Sci 7:134-140. https:// doi.org/10.1016/S1364-6613(03)00028-7

Moscicki MK, Reddon AR, Hurd PL (2011) Lateralized behaviour of a non-social cichlid fish (Amatitlania nigrofasciata) in a social and a non-social environment. Behav Process 88:27-32. https:// doi.org/10.1016/j.beproc.2011.07.004

Munteanu AM, Starnberger I, Pašukonis A, Bugnyar T, Hödl W, Fitch WT (2016) Take the long way home: behaviour of a neotropical frog, Allobates femoralis, in a detour task. Behav Process 126:71-75. https://doi.org/10.1016/j.beproc.2016.03.009

Murai T, Nakako T, Ikejiri M, Ikeda K (2013) Effects of lurasidone on executive function in common marmosets. Behav Brain Res 246:125-131. https://doi.org/10.1016/j.bbr.2013.02.019

Murphy J, Sutherland A, Arkins S (2005) Idiosyncratic motor laterality in the horse. Appl Anim Behav Sci 91:297-310. https://doi. org/10.1016/j.applanim.2004.11.001

Nawroth C, Baciadonna L, McElligott AG (2016) Goats learn socially from humans in a spatial problem-solving task. Anim Behav 121:123-129. https://doi.org/10.1016/j.anbehav.2016.09.004

Noland JS (2008) Executive functioning demands of the object retrieval task for 8-month-old infants. Child Neuropsychol 14:504-509. https://doi.org/10.1080/09297040701770819

Noland JS, Rodrigues NP (2012) Direct touches to clear barriers: developmental sensitivity of a new measure of the production of ineffective responses in infancy. Child Neuropsychol 18:506-511. https://doi.org/10.1080/09297049.2011.628307

Olausson P, Jentsch JD, Krueger DD, Tronson NC, Nairn AC, Taylor JR (2007) Orbitofrontal cortex and cognitive-motivational impairments in psychostimulant addiction. Ann NY Acad Sci 1121:610-638. https://doi.org/10.1196/annals.1401.016

Olkowicz S, Kocourek M, Lučan RK, Porteš M, Fitch WT, HerculanoHouzel S, Němec P (2016) Birds have primate-like numbers of neurons in the forebrain. Proc Natl Acad Sci USA 113:72557260. https://doi.org/10.1073/pnas.1517131113

Osthaus B, Marlow D, Ducat P (2010) Minding the gap: spatial perseveration error in dogs. Anim Cogn 13:881-885. https://doi. org/10.1007/s10071-010-0331-z

Osthaus B, Proops L, Hocking I, Burden F (2013) Spatial cognition and perseveration by horses, donkeys and mules in a simple A-notB detour task. Anim Cogn 16:301-305. https://doi.org/10.1007/ s10071-012-0589-4

Osvath M, Kabadayi C, Jacobs I (2014) Independent evolution of similar complex cognitive skills: the importance of embodied degrees of freedom. Anim Behav Cogn 1:249-264. https://doi. org/10.12966/abc.08.03.2014

Parker KJ, Buckmaster CL, Justus KR, Schatzberg AF, Lyons DM (2005) Mild early life stress enhances prefrontal-dependent response inhibition in monkeys. Biol Psychiatry 57:848-855. https://doi.org/10.1016/j.biopsych.2004.12.024

Parker KJ, Buckmaster CL, Lindley SE, Schatzberg AF, Lyons DM (2012) Hypothalamic-pituitary-adrenal axis physiology and cognitive control of behavior in stress inoculated monkeys. Int J Behav Dev 36:45-52. https://doi. org/10.1177/0165025411406864

Piaget J (1954) The construction of reality in the child. Basic Books, New York. https://doi.org/10.1037/11168-000

Pongracz P, Miklosi A, Kubinyi E, Gurobi K, Topál J, Csányi V (2001) Social learning in dogs: the effect of a human demonstrator on the performance of dogs in a detour task. Anim Behav 62:11091117. https://doi.org/10.1006/anbe.2001.1866

Pongracz P, Miklosi A, Kubinyi E, Topal J, Csanyi V (2003a) Interaction between individual experience and social learning in dogs. Anim Behav 65:595-603. https://doi.org/10.1006/ anbe.2003.2079

Pongracz P, Miklosi A, Timar-Geng K, Csanyi V (2003b) Preference for copying unambiguous demonstrations in dogs (Canis familiaris). J Comp Psychol 117:337. https://doi. org/10.1037/0735-7036.117.3.337

Pongrácz P, Miklósi Á, Vida V, Csányi V (2005) The pet dogs ability for learning from a human demonstrator in a detour task is independent from the breed and age. Appl Anim Behav Sci 90:309323. https://doi.org/10.1016/j.applanim.2004.08.004

Pongrácz P, Vida V, Bánhegyi P, Miklósi Á (2008) How does dominance rank status affect individual and social learning 
performance in the dog (Canis familiaris)? Anim Cogn 11:7582. https://doi.org/10.1007/s10071-007-0090-7

Ponticorvo M, Walker R, Miglino O (2007) Evolutionary robotics as a tool to investigate spatial cognition in artificial and natural systems. In: Loula A, Gudwin R, Queiroz J (eds) Artificial cognition systems. Idea Group Publishing, Hershey, pp 210-237. https:// doi.org/10.4018/978-1-59904-111-7

Poucet B, Thinus-Blanc C, Chapuis N (1983) Route planning in cats, in relation to the visibility of the goal. Anim Behav 31:594-599. https://doi.org/10.1016/s0003-3472(83)80083-9

Pryce CR, Dettling A, Spengler M, Spaete C, Feldon J (2004) Evidence for altered monoamine activity and emotional and cognitive disturbance in marmoset monkeys exposed to early life stress. Ann NY Acad Sci 1032:245-249. https://doi.org/10.1196/ annals. 1314.030

Rashotte ME (1987) Behavior in relation to objects in space: Some historical perspectives. In: Ellen P, Thinus-Blanc C (eds) Cognitive processes and spatial orientation in animal and man. Springer, La-Baume-les-Aix, pp 39-54. https://doi. org/10.1007/978-94-009-3531-0_3

Reddon AR, Gutiérrez-Ibáñez C, Wylie DR, Hurd PL (2009) The relationship between growth, brain asymmetry and behavioural lateralization in a cichlid fish. Behav Brain Res 201:223-228. https://doi.org/10.1016/j.bbr.2009.02.015

Redish AD (2016) Vicarious trial and error. Nat Rev Neurosci 17:147159. https://doi.org/10.1038/nrn.2015.30

Regolin L, Rose SP (1999) Long-term memory for a spatial task in young chicks. Anim Behav 57:1185-1191. https://doi. org/10.1006/anbe.1999.1097

Regolin L, Vallortigara G, Zanforlin M (1994) Perceptual and motivational aspects of detour behaviour in young chicks. Anim Behav 47:123-131. https://doi.org/10.1006/anbe.1994.1014

Regolin L, Vallortigara G, Zanforlin M (1995) Object and spatial representations in detour problems by chicks. Anim Behav 49:195199. https://doi.org/10.1016/0003-3472(95)80167-7

Roitberg BZ, Emborg ME, Sramek JG, Palfi S, Kordower JH (2002) Behavioral and morphological comparison of two nonhuman primate models of Huntington's disease. J Neurosurg 50:137-146. https://doi.org/10.1227/00006123-200201000-00022

Rørvang MV, Ahrendt LP, Christensen JW (2015) Horses fail to use social learning when solving spatial detour tasks. Anim Cogn 18:847-854. https://doi.org/10.1007/s10071-015-0852-6

Rosati AG, Wobber V, Hughes K, Santos LR (2014) Comparative developmental psychology: How is human cognitive development unique? Evol Psychol 12:448-473. https://doi. org/10.1177/147470491401200211

Rutten K, Basile JL, Prickaerts J, Blokland A, Vivian JA (2008) Selective PDE inhibitors rolipram and sildenafil improve object retrieval performance in adult cynomolgus macaques. Psychopharmacology 196:643-648. https://doi.org/10.1007/ s00213-007-0999-1

Santos LR, Ericson BN, Hauser MD (1999) Constraints on problem solving and inhibition: object retrieval in cotton-top tamarins (Saguinus oedipus oedipus). J Comp Psychol 113:186-193. https://doi.org/10.1037/0735-7036.113.2.186

Sarris EG (1937) Die individuellen Unterschiede bei Hunden. Zeitschrift für Angewandte Psychologie und Charakterkunde 52:257-309

Savin H, Randle H (2013) Problem solving in the horse (Equus caballus) using a detour task. J Vet Behav 8:e19-e20. https://doi. org/10.1007/s10164-010-0246-9

Schiller PH (1948) Delayed response in the minnow. J Comp Physiol Psychol 41:233-238. https://doi.org/10.1037/h0055275

Schiller PH (1949a) Analysis of detour behavior. I. Learning of roundabout pathways in fish. J Comp Physiol Psychol 42:463-475. https://doi.org/10.1037/h0055223
Schiller PH (1949b) Delayed detour response in the octopus. J Comp Physiol Psychol 42:220-225. https://doi.org/10.1037/h0056879

Schiller PH (1950) Analysis of detour behavior: IV. Congruent and incongruent detour behavior in cats. J Exp Psychol 40:217-227. https://doi.org/10.1037/h0062706

Schneider JS, Pope-Coleman A (1995) Cognitive deficits precede motor deficits in a slowly progressing model of parkinsonism in the monkey. Neurodegeneration 4:245-255. https://doi. org/10.1016/1055-8330(95)90014-4

Schneider JS, Roeltgen DP (1993) Delayed matching-to-sample, object retrieval, and discrimination reversal deficits in chronic low dose MPTP-treated monkeys. Brain Res 615:351-354. https://doi. org/10.1016/0006-8993(93)90049-s

Schneider JS, Van Velson M, Menzaghi F, Lloyd GK (1998) Effects of the nicotinic acetylcholine receptor agonist SIB-1508Y on object retrieval performance in MPTP-treated monkeys: comparison with levodopa treatment. Ann Neurol 43:311-317

Scholes NW (1965) Detour learning and development in the domestic chick. J Comp Physiol Psychol 60:114-116. https://doi. org/10.1037/h0022335

Scholes NW, Wheaton LG (1966) Critical period for detour learning in developing chicks. Life Sci 5:1859-1865. https://doi. org/10.1016/0024-3205(66)90280-3

Scott JP, Fuller JL (1965) Genetics and the social behavior of the dog. University of Chicago Press, Chicago

Shaw RC (2017) Testing cognition in the wild: factors affecting performance and individual consistency in two measures of avian cognition. Behav Proc 134:31-36. https://doi.org/10.1016/j. beproc.2016.06.004

Shaw RC, Boogert NJ, Clayton NS, Burns KC (2015) Wild psychometrics: evidence for 'general' cognitive performance in wild New Zealand robins, Petroica longipes. Anim Behav 109:101-111. https://doi.org/10.1016/j.anbehav.2015.08.001

Shearer A, Atkinson JW (2001) Comparative analysis of food-finding behavior of an herbivorous and a carnivorous land snail. Invertebr Biol 120:199-205. https://doi.org/10.1111/j.1744-7410.2001. tb00030.x

Siniscalchi M, Pergola G, Quaranta A (2013) Detour behaviour in attack-trained dogs: left-turners perform better than rightturners. Laterality 18:282-293. https://doi.org/10.1080/13576 50X.2012.662234

Smith BP, Litchfield CA (2010) How well do dingoes, Canis dingo, perform on the detour task? Anim Behav 80:155-162. https:// doi.org/10.1016/j.anbehav.2010.04.017

Smith SM, Uslaner JM, Cox CD, Huszar SL, Cannon CE, Vardigan JD, Eddins D, Toolan DM, Kandebo M, Yao L, Raheem IT, Schreier JD, Breslin MJ, Coleman PJ, Renger JJ (2013) The novel phosphodiesterase 10A inhibitor THPP-1 has antipsychotic-like effects in rat and improves cognition in rat and rhesus monkey. Neuropharmacol 64:215-223. https://doi.org/10.1016/j. neuropharm.2012.06.013

Spigel IM (1964) Learning, retention, and disruption of detour behavior in the turtle. J Comp Physiol Psychol 57:108-112

Sun H, Che Y, Liu X, Ma Y (2010) Detour behavior changes associated with prenatal morphine exposure in 11-day-old chicks. Int J Dev Neurosci 28:239-243. https://doi.org/10.1016/j. ijdevneu.2010.02.001

Sutcliffe JS, Beaumont V, Watson JM et al (2014) Efficacy of selective PDE4D negative allosteric modulators in the object retrieval task in female cynomolgus monkeys (Macaca fascicularis). PLoS ONE 9:e102449. https://doi.org/10.1371/journal.pone.0102449

Tarsitano M (2006) Route selection by a jumping spider (Portia labiata) during the locomotory phase of a detour. Anim Behav 72:1437-1442. https://doi.org/10.1016/j.anbehav.2006.05.007 
Tarsitano MS, Andrew R (1999) Scanning and route selection in the jumping spider Portia labiata. Anim Behav 58:255-265. https:// doi.org/10.1006/anbe.1999.1138

Tarsitano M, Jackson RR (1994) Jumping spiders make predatory detours requiring movement away from prey. Behaviour 131:6573. https://doi.org/10.1163/156853994x00217

Tarsitano MS, Jackson RR (1997) Araneophagic jumping spiders discriminate between detour routes that do and do not lead to prey. Anim Behav 53:257-266. https://doi.org/10.1006/ anbe. 1996.0372

Taylor J, Elsworth J, Roth R, Sladek J, Redmond D (1990a) Cognitive and motor deficits in the acquisition of an object retrieval/detour task in MPTP-treated monkeys. Brain 113:617-637. https://doi. org/10.1093/brain/113.3.617

Taylor J, Roth R, Sladek J, Redmond D (1990b) Cognitive and motor deficits in the performance of an object retrieval task with a barrier-detour in monkeys (Cercopithecus aethiops sabaeus) treated with MPTP: long-term performance and effect of transparency of the barrier. Behav Neurosci 104:564-576. https://doi. org/10.1037//0735-7044.104.4.564

Thelen E, Schöner G, Scheier C, Smith LB (2001) The dynamics of embodiment: a field theory of infant perseverative reaching. Behav Brain Sci 24:1-34. https://doi.org/10.1017/ s0140525x01003910

Thompson WR, Heron W (1954) The effects of restricting early experience on the problem-solving capacity of dogs. Can J Exp Psychol 8:17-31. https://doi.org/10.1037/h0083595

Thorndike EL (1911) Animal intelligence: experimental studies. The Macmillan Company, New York

Thornton A, Isden J, Madden JR (2014) Toward wild psychometrics: linking individual cognitive differences to fitness. Behav Ecol 25:1299-1301. https://doi.org/10.1093/beheco/aru095

Tolman EC (1932) Lewin's concept of vectors. J Gen Psychol 7:3-15. https://doi.org/10.1080/00221309.1932.9918444

Uslaner JM, Eddins D, Puri V et al (2013) The muscarinic M1 receptor positive allosteric modulator PQCA improves cognitive measures in rat, cynomolgus macaque, and rhesus macaque. Psychopharmacol 225:21-30. https://doi.org/10.1007/s00213-012-2788-8

Vallortigara G, Regolin L (2002) Facing an obstacle: lateralization of object and spatial cognition. In: Rogers LJ (ed) Comparative vertebrate lateralization. Cambridge University Press, Cambridge, pp 383-444. https://doi.org/10.1017/cbo9780511546372.013

Veit L, Nieder A (2013) Abstract rule neurons in the endbrain support intelligent behaviour in corvid songbirds. Nat Commun 4:2878. https://doi.org/10.1038/ncomms3878

Verbruggen F, Best M, Bowditch WA, Stevens T, McLaren IP (2014) The inhibitory control reflex. Neuropsychologia 65:263-278. https://doi.org/10.1016/j.neuropsychologia.2014.08.014

Vernouillet A, Anderson J, Clary D, Kelly DM (2016) Inhibition in Clark's nutcrackers (Nucifraga columbiana): results of a detourreaching test. Anim Cogn 19:661-665. https://doi.org/10.1007/ s10071-016-0952-y
Versace E, Morgante M, Pulina G, Vallortigara G (2007) Behavioural lateralization in sheep (Ovis aries). Behav Brain Res 184:72-80. https://doi.org/10.1016/j.bbr.2007.06.016

Vlamings PH, Hare B, Call J (2010) Reaching around barriers: the performance of the great apes and 3-5-year-old children. Anim Cogn 13:273-285. https://doi.org/10.1007/s10071-009-0265-5

Walker R, Miglino O (1999) Replicating experiments in "detour behavior" with artificially evolved robots: an A-life approach to comparative psychology. In: Floreano D, Nicoud JD, Mondada F (eds) Advances in artificial life. Springer, Berlin, pp 205-214. https://doi.org/10.1007/3-540-48304-7_27

Walker S, Mikheenko Y, Argyle L, Robbins T, Roberts A (2006) Selective prefrontal serotonin depletion impairs acquisition of a detour-reaching task. Eur J Neurosci 23:3119-3123. https://doi. org/10.1111/j.1460-9568.2006.04826.x

Wallis J, Dias R, Robbins T, Roberts AC (2001) Dissociable contributions of the orbitofrontal and lateral prefrontal cortex of the marmoset to performance on a detour reaching task. Eur J Neurosci 13:1797-1808. https://doi. org/10.1046/j.0953-816x.2001.01546.x

Wells M (1964) Detour experiments with octopuses. J Exp Biol 41:621-642

Wells M (1967) Short-term learning and interocular transfer in detour experiments with octopuses. J Exp Biol 47:393-408

Wells M (1970) Detour experiments with split-brain octopuses. J Exp Biol 53:375-389

Wilkinson A, Kuenstner K, Mueller J, Huber L (2010) Social learning in a non-social reptile (Geochelone carbonaria). Biol Lett 6:614-616. https://doi.org/10.1098/rsbl.2010.0092

Williams JL, Corbetta D, Cobb L (2015) How perception, action, functional value, and context can shape the development of infant reaching. Mov Sport Sci 89:5-15. https://doi.org/10.1051/ $\mathrm{sm} / 2015005$

Wynne C, Leguet B (2004) Detour behavior in the Quokka (Setonix brachyurus). Behav Process 67:281-286. https://doi. org/10.1016/j.beproc.2004.04.007

Wyrwicka W (1959) Studies on detour behaviour. Behaviour 14:240 264. https://doi.org/10.1163/156853959x00090

Zelazo PD, Frye D, Rapus T (1996) An age-related dissociation between knowing rules and using them. Cogn Dev 11:37-63. https://doi.org/10.1016/S0885-2014(96)90027-1

Zucca P, Sovrano VA (2008) Animal lateralization and social recognition: quails use their left visual hemifield when approaching a companion and their right visual hemifield when approaching a stranger. Cortex 44:13-20. https://doi.org/10.1016/j. cortex.2006.01

Zucca P, Antonelli F, Vallortigara G (2005) Detour behaviour in three species of birds: quails (Coturnix sp.), herring gulls (Larus cachinnans) and canaries (Serinus canaria). Anim Cogn 8:122-128. https://doi.org/10.1007/s10071-004-0243-x 